\title{
ENVIRONMENTAL DEA METHOD FOR ASSESSING PRODUCTIVITY OF EUROPEAN COUNTRIES
}

\author{
Ewa CHODAKOWSKA, Joanicjusz NAZARKO \\ Bialystok University of Technology, ul. Wiejska 45A, 15-351 Bialystok, Poland
}

Received 15 May 2016; accepted 11 December 2016

\begin{abstract}
The article presents the concept of environmental efficiency analysis based on the method of Data Envelopment Analysis in the case of the existence of desirable and undesirable results. Theoretical considerations are illustrated by a case study of European countries and evaluation of productivity taking into account not only economic growth but also effects which are undesirable and impossible to eliminate entirely, such as the impact on the environment. The differences in the results are explained by the relationship between policies aiming at supporting research and development with the use of the Tobit regression model. The added value of this work is to propose an integration of environmental DEA method with the concept of technological competitors. The possibility of applying the concept of DEA to technological competition was presented in the form of classification and benchmarking of the European countries. It is concluded that European countries are highly diversified in regard to the efficiency of environmental performance.
\end{abstract}

Keywords: environmental performance, data envelopment analysis (DEA), undesirable outputs, efficiency, Tobit regression, benchmarking.

JEL Classification: C44, O44.

\section{Introduction}

In the last few decades the awareness of the negative impact of economic development on the environment has led to a considerable amount of research on the issue concerning measurement of sustainable development. From the political and economic point of view, a perfect indicator (or a number of indicators) of sustainable development should make it possible not only to make objective comparisons but also to assess the influence of different types of regulations, e.g. taxes, pollution standards, permits Tyteca (1996).

From a wide range of different methods of constructing environmental performance indicators (EPIs), environmental DEA method - an expanded version of Data Envelopment Analysis (DEA), has gained popularity and recognition in recent years (Zhou et al. 2008b).

Corresponding author Joanicjusz Nazarko

E-mail: joanicjusz.nazarko@gmail.com 
The concept of environmental DEA was introduced by Färe et al. (1989). They developed and implemented a performance index based on the DEA method that allows the multilateral productivity comparison of units producing multiple outputs, some of which are undesirable. Later, Callens and Tyteca (1999) proposed indicators to measure sustainable development based on the DEA frontier concept. In their work, the economic, social and environmental efficiency was indicated as indispensable to assess sustainable development. One of the recent positions among theoretical publications is Guo and $\mathrm{Wu}$ (2013) who extend the DEA model to incorporate undesirable outputs (like pollution) in order to construct a unique ranking based on "the optimal shadow prices" when analyzing the units that get the same efficiency score in the traditional DEA model. Sueyoshi and Yuan (2015) in turn, suggested the solution to the problem of zeros and negative values in the data set during the assessment of the environmental efficiency with use of DEA.

Throughout the application works, environmental DEA method was used to assess the environmental performance of units of different scale: regions, countries, provinces, sectors, and firms. Especially many publications have been dedicated to the assessment of the situation in China. The quickly developing Chinese economy is also highly energy consuming and highly polluting. Globally, China emits the most of carbon dioxide $\left(\mathrm{CO}_{2}\right)$ and sulfur dioxide $\left(\mathrm{SO}_{2}\right)$ (EPA 2014).

Meng et al. (2013) presented a static and a dynamic non-radial DEA environmental performance indicator for measuring the environmental performance of the industrial sectors in China during the period of 1998-2009. The presented approach was tested on the basis of two inputs: industrial labour force and energy consumption, one desired output: industrial value added, and undesirable outputs: industrial $\mathrm{CO}_{2}$, waste gas, waste water and solid waste. The analysis allowed to conclude that there was an improvement in environmental performance.

The energy efficiency of the China's 36 industrial sectors was also analyzed by Li and Shi (2014). They regressed efficiency obtained using the slack-based super efficiency DEA model against possible influencing factors such as government regulations, technology innovations, industry structure and energy consumption.

Lin and Fei (2015) concentrate on differences only in the agricultural sector and evaluate environmental performance in 2003-2010 of provinces by DEA with the use of the Malmquist index and Theil index methodology.

Conclusions indicating the improvement in environmental efficiency were also derived from (Yang et al. 2015) research. The super-efficiency model was employed to assess the situation in the provinces in China during the period from 2000 to 2010 . The data used in the study included labour, capital investment, energy consumption, $\mathrm{CO}_{2}$ and $\mathrm{SO}_{2}$ emissions as input and GDP as the output. The analysis revealed that although the regional environmental efficiency in China generally experienced improvements during the studied period there were regional disparities.

Meta-frontier and DEA (Wang et al. 2015) were used to investigate the efficiency of environmental protection mechanisms and economic development of over two hundred cities in China. Meta-frontier was obtained by enveloping groups of cities with different 
production technologies. Environmental efficiency was calculated using the variable returns to scale DEA model. The main conclusion is that the overall environmental efficiency of Chinese cities is low when the most advanced production technology is taken as the reference frontier technology. The differences in environmental efficiency between frontiers (meta and groups) allow to evaluate the heterogeneity of production technologies.

Similar methodology (Li, Wang 2014) was used to assess 95 countries classified into four groups with respect to technology.

Going back to China, Wang et al. (2013) analyzed the total-factor energy and environmental efficiency of the administrative regions of China from 2000 to 2008. This paper utilized the DEA model with desirable and undesirable outputs and DEA window analysis to measure the changes in time. According to their work, the eastern regions in China perform better than the central and western ones and the overall efficiency of China slightly increased in the analyzed period.

Wu et al. (2012) proposed several environmental DEA models to measure energy efficiency performance for provinces in China from 1997 to 2008 and divided the estimated index into components. The analyzed examples show the potential improvement in the reduction of energy consumption and the positive impact of technological improvement on energy efficiency.

With regard to the works comparing the environmental efficiency of different countries with the use of DEA, such analyses were performed inter alia by Zaim and Taskin (2000), Färe et al. (2004), Zhou et al. (2007), Lozano and Gutiérrez (2008) or Zhou et al. (2012).

Zaim and Taskin (2000) applied the environmental production frontier methodology to compare 25 OECD countries in regard to environmental efficiency from 1980 to 1990. They took into account real GDP (as the desirable output), $\mathrm{CO}_{2}$ (as the undesirable output) as well as total employment and total capital stock (as the inputs).

Färe et al. (2004) provided the index of environmental performance that could be calculated using DEA linear programing and applied the proposed approach to a sample of OECD countries in 1990.

Zhou et al. (2007) used a non-radial DEA model with a greater discriminatory power than the radial ones and modelled the environmental performance of 26 OECD countries in the period of 1995-1997. Based on the rankings of the efficiency of the transformation of workforce and energy into GDP, taking into account undesirable products such as: $\mathrm{CO}_{2}$, $\mathrm{SO}_{\mathrm{x}}, \mathrm{NO}_{\mathrm{x}}$ and $\mathrm{CO}$, it was noted that countries experienced improvement in environmental performance.

Lozano and Gutiérrez (2008) proposed several non-parametric frontier approaches based on the DEA to model the relationships between the population, energy consumption, greenhouse gases emission, and GDP. The data sample consisted of most of the countries that are listed in the Kyoto Protocol.

Zhou et al. (2012) analyzed the production efficiency of counties' electricity generation with the use of a non-radial directional distance function. They took into account fossil fuel consumption as input, the electricity generated by fossil-fuel power plants as desirable output and the total $\mathrm{CO}_{2}$ emissions from these plants as undesirable output in the year 
2005. They analyzed 126 countries classified into two groups: without combined heat and power plants (mainly non-OECD countries) and with such plants (mainly OECD countries). According to their work OECD countries had better carbon emission performance and integrated energy-carbon performance than non-OECD countries in electricity generation, while the differences in energy performance were not significant.

Some studies in literature expanded the analysis from a cross-country case to crossregion benchmarking. For instance, Zhou et al. (2008a) applied the environmental DEA to investigate the performances of 8 world regions. They measured and discussed environmental performance assessed by different environmental DEA models with regards to returns to scale: non-increasing and variant. They considered total energy consumption, GDP and $\mathrm{CO}_{2}$ in 2002.

Measuring the environmental efficiency of individual companies is limited by the availability of data which the companies share with reluctance. Because of that the majority of works evaluate electricity generation plants or electricity distribution utilities. Moreover, in most of the works, traditional, classic DEA models were used (Zhou et al. 2008b). The possibilities of applying the DEA environmental concept were presented for example by Färe et al. (1996) who applied EPIs for the United States fossil-fuel electric utilities. The considered input variables were: installed generating capacity (that represented capital), employment and three categories of fuel (coal, oil and gas), annual production of electricity and annual emissions of $\mathrm{SO}_{2}$, $\mathrm{NOx}$ and $\mathrm{CO}_{2}$.

Sueyoshi et al. (2010) analyzed operational efficiency, environmental efficiency and unified efficiency of the United States coal-fired power plants with the use of non-radial DEA. The data used as input included: the number of employees, investment costs, total non-fuel operating and maintenance expenditures and fuel consumption. The desirable and undesirable outputs were respectively: $\mathrm{GWh}$, the total amount of $\mathrm{SO}_{2}, \mathrm{NOx}$ and $\mathrm{CO}_{2}$.

Many researchers undertook the evaluation of the efficiency of the sectors of the economy. Makridou et al. (2016) concentrated on the most energy intensive sectors in EU countries. The methodology used was DEA combined with Malmquist index to analyze the trends in time and multilevel linear regression to detect the most significant factors affecting the estimated efficiency. Positive conclusions of the increase in overall efficiency were derived from the analysis.

DEA EPIs allowed (Baležentis et al. 2016) to group the Lithuanian economic sectors in terms of EPIs and growth rate. EPIs were assessed on the basis of gross value added, worked hours, capital stock and $\mathrm{CO}_{2}, \mathrm{~N}_{2} \mathrm{O}$ emissions. As expected, the most inefficient sectors turned out to be petroleum production and air transport.

It is also worth to mention an interesting work that is a survey of DEA applications in energy and environmental studies from the period of 1983-2006 (Zhou et al. 2008b). The authors presented the most popular DEA methodology and classified 100 publications on the topic.

This article presents the environmental concept of productivity analysis, based on Data Envelopment Analysis that takes into account the desirable and undesirable outputs of development in order to assess the performance of European countries. In Europe, there 
is a strong tendency to centrally deploy various kinds of arrangements restricting the currently used technologies and to promote the others. There is a constant emphasis on the need for sustainable development, investment in innovative technologies by continuous and increased spending on research and development (R\&D). Firstly, the differences and similarities between countries were presented. Then, using traditional and environmental DEA method, the authors evaluated the productivity of European countries. The obtained EPIs were regressed against $R \& D$ expenses to test the relationship between them. Finally, the possibility of applying the concept of DEA technological competition was presented for the classification and benchmarking of countries.

\section{Framework of environmental Data Envelopment Analysis technology}

Data Envelopment Analysis (DEA), initially proposed by Charnes et al. (1978), is a wellestablished method for measuring the relative efficiency of a set of homogeneous decision making units (DMUs). Basic DEA allows to evaluate systems with multiple inputs and outputs. It provides a synthetic indicator that takes into account the strengths of each analyzed unit. The idea of DEA is presented in Figure 1.

Since its introduction, DEA models were modified, altered and supplemented. One of the most important development was the possibility to accommodate the non-controllable, non-discretionary factors in the DEA, which affect the efficiency but are not subject to control or management (Fig. 2).

There have also been developed DEA models that deal with the undesirable but unavoidable weak disposable outputs, and accommodate such variables in the analysis (Fig. 3). Such models are applied in the construction of EPIs.

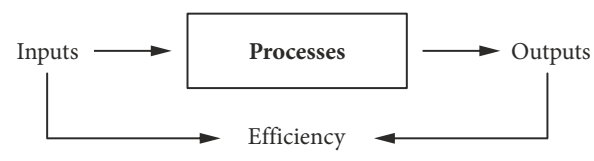

Fig. 1. The idea of the DEA

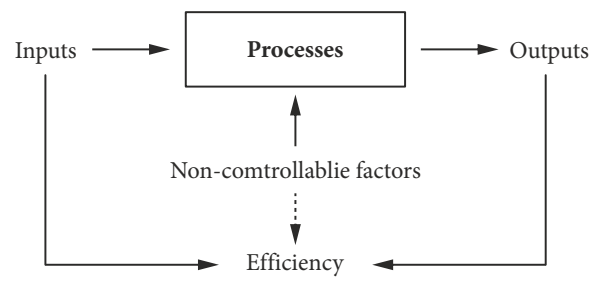

Fig. 2. The idea of the DEA with non-controllable factors

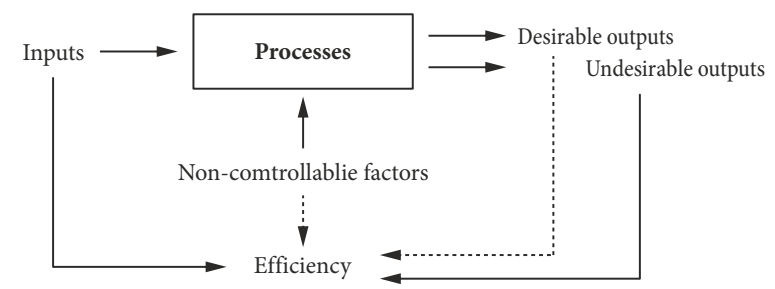

Fig. 3. The idea of the DEA with non-controllable factors and undesirable outputs 
Mathematically, the idea of DEA is that for each DMU, using linear programming techniques, such weights' combination is sought so as to maximize the ratio of the weighted sum of outputs and inputs:

$$
\begin{gathered}
\max \frac{\sum_{n}^{N} v_{n} y_{n}}{\sum_{m}^{M} u_{m} x_{m}} ; \\
\frac{\sum_{n}^{N} v_{n} y_{n}}{\sum_{m}^{M} u_{m} x_{m}} \leq 1 ; \\
u_{m} \geq 0, v_{n} \geq 0,
\end{gathered}
$$

where: $x_{m}-m$-th input; $y_{n}-n$-th output; $u_{m}$ - weight of the input $x_{m} ; v_{n}$ - weight of the output $y_{n} ; M$ - number of inputs; $N$ - number of outputs.

For the efficient units that value is 1 . If there is no such weights' combination where the quotient (1) assumes the value 1, the unit is non-efficient.

The basic input-oriented radial DEA model (CCR-I DEA) for evaluating efficiency of $\mathrm{DMU}_{\mathrm{O}}$ may be described as Cooper et al. (2007):

$$
\begin{aligned}
& \quad \min \theta ; \\
& \sum_{i=1}^{I} \lambda_{i} x_{i m} \leq \theta x_{O m}, \quad m=1, \ldots, M ; \\
& \sum_{i=1}^{I} \lambda_{i} y_{i n} \geq y_{O n}, \quad n=1, \ldots, N ; \\
& \lambda_{i} \geq 0, \quad i=1, \ldots, I,
\end{aligned}
$$

where:

$$
\begin{aligned}
& X_{i}=\left(x_{i 1}, x_{i 2}, x_{i 3}, \ldots, x_{i M}\right) \text { - input vector; } \\
& Y_{i}=\left(y_{i 1}, y_{i 2}, y_{i 3}, \ldots, y_{i N}\right) \text { - } \text { output vector; } \\
& \lambda_{i} \text { - vector of weights specifying the intensity of the use of refer- } \\
& \quad \text { ence objects' technologies in optimal } i \text {-th DMU's technology; } \\
& n=1,2, \ldots, N \text { - number of outputs; } \\
& m=1,2, \ldots, M \text { - number of inputs; } \\
& i=1,2, \ldots, I \text { - number of DMUs; } \\
& \theta \text { - efficiency ratio taking values in the range }<0.1>; 1 \text { for fully ef- } \\
& \quad \text { ficient DMUs. The larger } \theta \text { is, the better efficiency DMU has. }
\end{aligned}
$$

The idea of DEA in simple cases of limited number of inputs and outputs can be presented and solved graphically. Fully efficient units create an efficiency frontier. The possibility of improving the efficiency of inefficient units is determined by referencing their results to the efficient frontier. The case involving one input and two outputs is shown in Figure 4. Units A, B and C have the same input value but different output values. Units A and C create the frontier that limits the production capability of a region. Inefficient unit $\mathrm{B}$ can be evaluated by referring to the points on frontier surface - e.g. B' or B'. The movement to B' can be achieved by proportionally increasing both outputs and keeping the status quo for the input, while the movement to B" - by reducing the input and keeping constant outputs. 
There is a variety of possible ways to adjust the DEA to accommodate non-controllable factors. One of the most popular is the two stage approach involving solving the DEA model in the first step and then correcting the results through the use of the coefficients of a regression model. Among regression models, the Tobit model that can account for truncated data can be recommended. The Tobit model, introduced by Tobin (1958), assumes that the dependent variable has its value censored. The idea of Tobit regression is presented in Figure 5.

The standard Tobit model for the latent, unobserved variable $-y_{i}^{*}$, that linearly depends on the vector $x_{i}$ and the observed non-negative variable $y_{i}$ can be expressed as:

$$
y_{i}=\left\{\begin{array}{c}
y_{i}^{*} \text { if } y_{i}^{*}>0 \\
0 \text { if } y_{i}^{*} \leq 0
\end{array},\right.
$$

where: $y_{i}^{*}=\beta x_{i}+\varepsilon_{i} ; \varepsilon_{i} \sim n\left(0, \sigma^{2}\right)$.

The Tobit model is estimated via maximum likelihood.

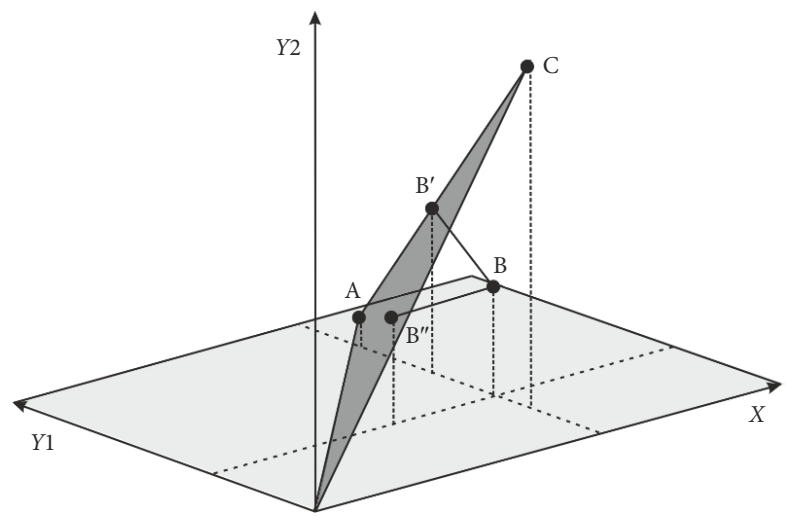

Fig. 4. Production frontier - a case of two outputs and a single input

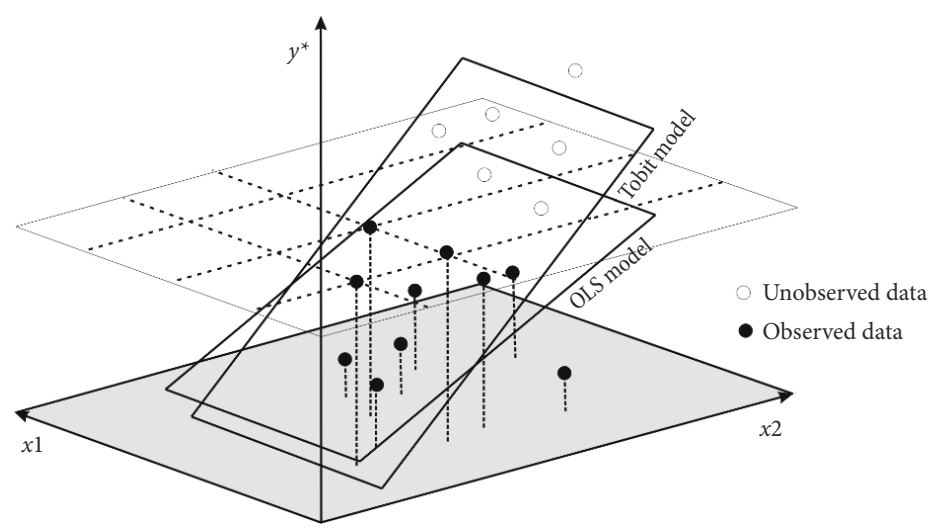

Fig. 5. Tobit model 
To measure the environmental performance through DEA, the concept of environmental DEA technology, originally suggested by Färe et al. (1989), can be used. As regards technology all outputs are classified into desirable and undesirable outputs. The following two assumptions are adopted: outputs are weakly disposable and desirable outputs and undesirable outputs are null-joint. This implies that only the proportional reduction in desirable and undesirable outputs is feasible. It is not possible to reduce solely undesirable outputs. Moreover, undesirable outputs constitute integrated elements of the production process and they must be produced while producing the desirable outputs. The only way to eliminate all the undesirable outputs is to end the production process (Meng et al. 2013). The DEA Radial Environmental Index (REI) model for measuring the environmental productivity of DMUo can be written as (Meng et al. 2013):

$$
\begin{aligned}
& R E I\left(X_{O}, Y_{O}, Q_{O}\right)=\min \theta ; \\
& \sum_{i=1}^{I} \lambda_{i} x_{i m} \leq x_{O m}, m=1, \ldots, M ; \\
& \sum_{i=1}^{I} \lambda_{i} y_{i n} \geq y_{O n}, n=1, \ldots, N ; \\
& \sum_{i=1}^{I} \lambda_{i} q_{i j} \leq \theta q_{O j}, j=1, \ldots, J ; \\
& \lambda_{i} \geq 0, i=1, \ldots, I,
\end{aligned}
$$

where:

$\mathrm{X}_{i}=\left(x_{i 1}, x_{i 2}, x_{i 3}, \ldots, x_{i M}\right)-$ input vector,

$\mathrm{Y}_{i}=\left(y_{i 1}, y_{i 2}, y_{i 3}, \ldots, y_{i N}\right)-$ desirable output vector,

$Q_{i}=\left(q_{i 1}, q_{i 2}, q_{i 3}, \ldots, q_{i J}\right)-$ undesirable output vector,

$\lambda_{i}-$ vector of weights specifying the intensity of the use of reference objects' technologies in optimal $i$-th DMU's technology.

If a specific DMU has a larger REI, it has better environmental performance (Zhou et al. 2008a).

Figure 6 illustrates a simple case with one desirable output, one undesirable output, and one input. DMUs A and E use the identical value of input to produce the same amount of desirable output but have a different undesirable output value, which is the result of their technologies. DMU A used a less polluting, environmentally high-level technology.

Figure 6 also illustrates the difference between strong and weak disposability in case of a few DMSs: All DMUs use equal input to produce the desirable and undesirable outputs. Assuming strong disposability of undesirable outputs, the reference output set is the region bounded by FBCD. Weak disposability of the undesirable outputs changes the outputs set to $\mathrm{ABCD}$. There is also a possibility to distinguish the various levels of disposability among undesirable outputs. Such suggestion could be found inter alia in (Yang, Pollitt 2010).

In this article, in order to evaluate the environmental performance of European countries, the steps presented in the schema in Figure 7 were implemented. All calculations, except the estimations of Tobit regression parameters, were made in Microsoft Excel, Solver 


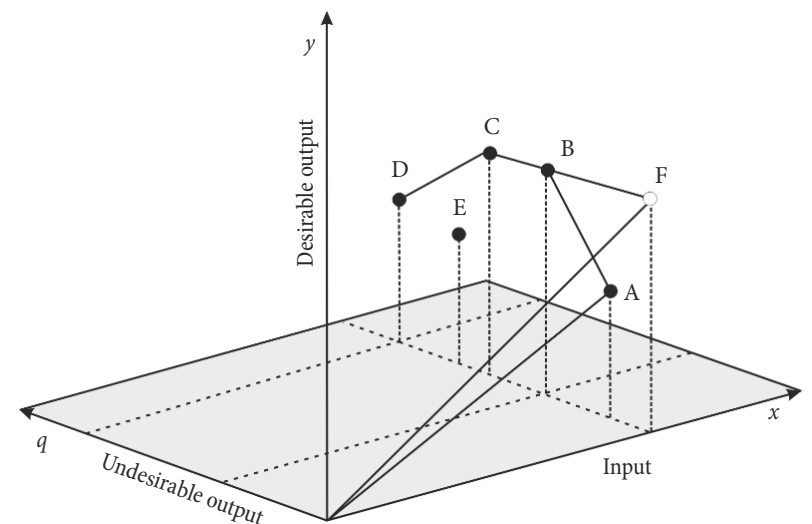

Fig. 6. Production set with one input, one desirable output, and one undesirable output

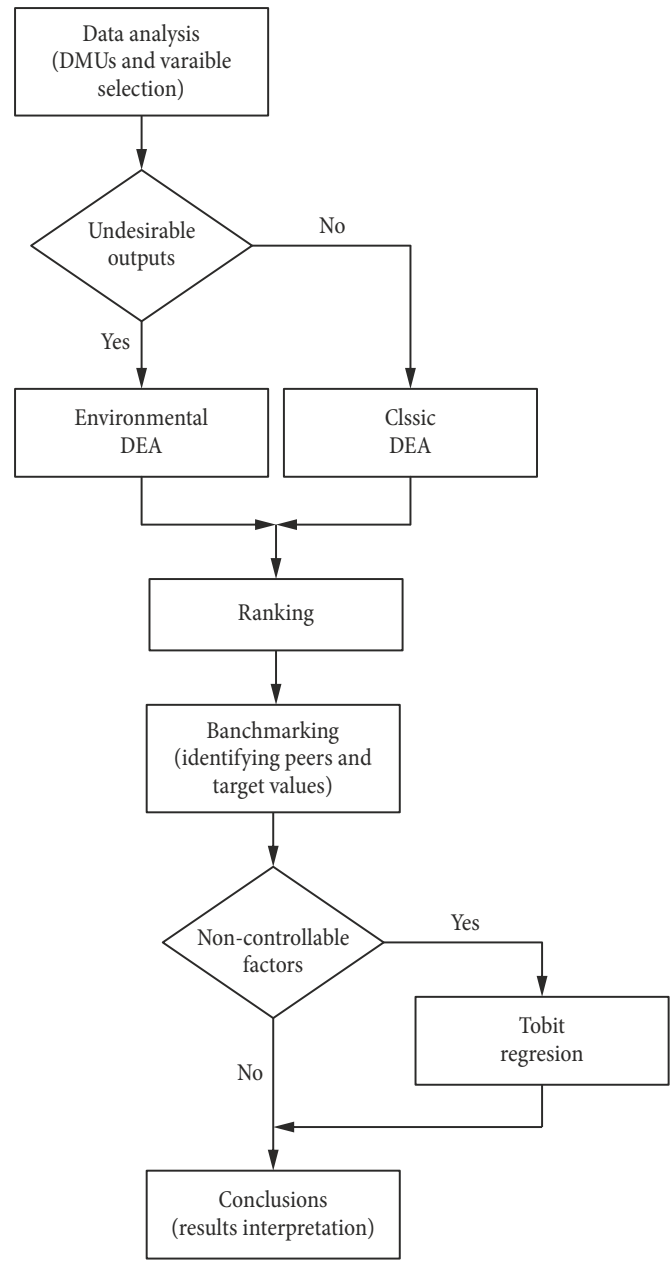

Fig. 7. Algorithm of the proposed framework of analysis 
add-in and automating work using VBA. The Tobit model statistic was estimated using EasyReg (by H. J. Bierens 2015).

The initial, preparatory work included DMUs identification, selection of the evaluation criteria, and the collection of the values of variables. Usually, selection of variables is the most essential but, at the same time, the most difficult aspect of DEA analysis (Nazarko, Šaparauskas 2014). The next step involved the performance assessment of the chosen European countries using the traditional or/and environmental DEA technology. Then rankings, were built according to the criteria, and relevant target values and peers were defined. Benchmarking can be developed to compare objects on the basis of optimal technology that consists of fully efficient units, characteristic of the DEA model or using the concept of technological competitions. The next stage of the analysis was the consideration of the existence of non-controllable factors affecting DEA scores and the effect of regression upon the efficiency estimation. The resulting interpretation along with conclusions and proposals for further consideration concluded the study. The proposed framework is universal and can be seen as a general way to obtain DEA EPIs.

\section{Data}

In this paper the DEA concept of environmental performance was used to asses 24 European countries beginning from the year 2013. On the basis of the justifications contained in the literature, labour force (population aged 15 to 64 - LF) and primary energy consumption (million tonnes oil equivalent - PEC) were employed as two inputs for the research. Gross domestic product at market prices (GDP) was the only desirable output. Carbon dioxide emissions $\left(\mathrm{CO}_{2}\right)$ were chosen as an undesirable output. The data on LF and GDP was collected from Eurostat (Eurostat 2014), the recent data on PEC and $\mathrm{CO}_{2}$ came from the BP Statistical Review of World Energy 2014 (BP Statistical Review of World Energy 2014). The selected countries are listed in Table 4. The data is shown on Figures 8 and 9 and the descriptive statistics of the variables analyzed are presented in Table 1.
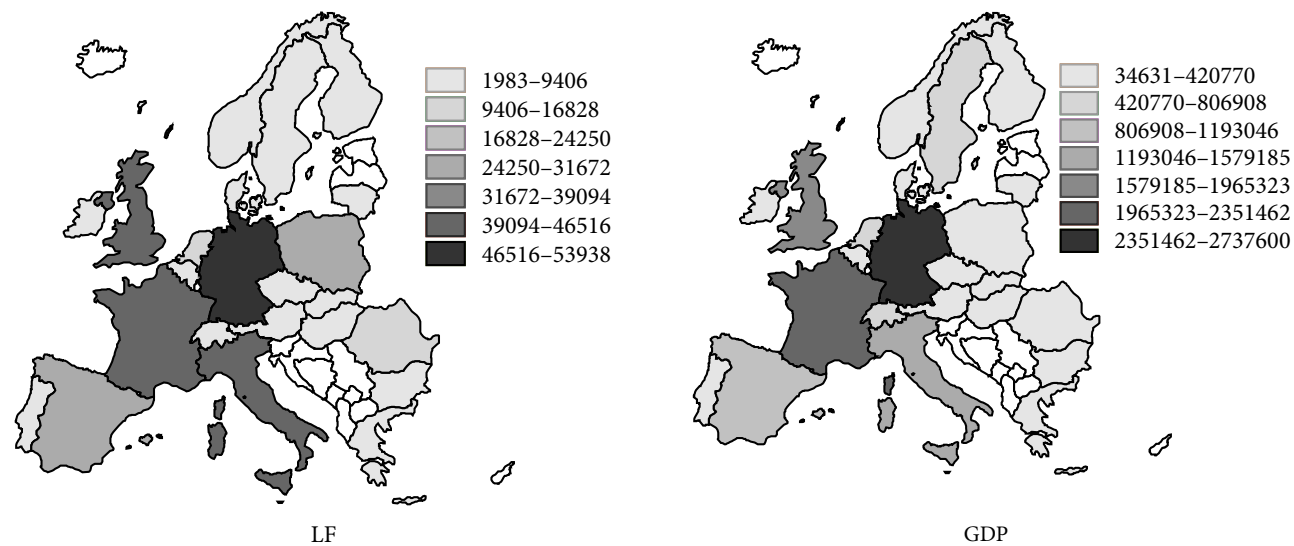

Fig. 8. Labour force in thousands and GDP in market price in millions of euro 


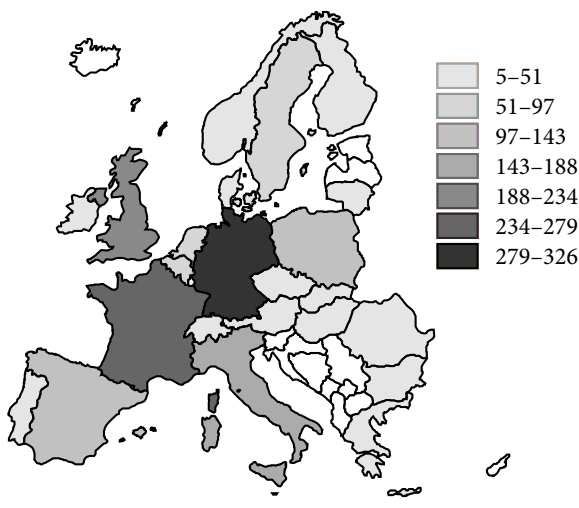

PEC

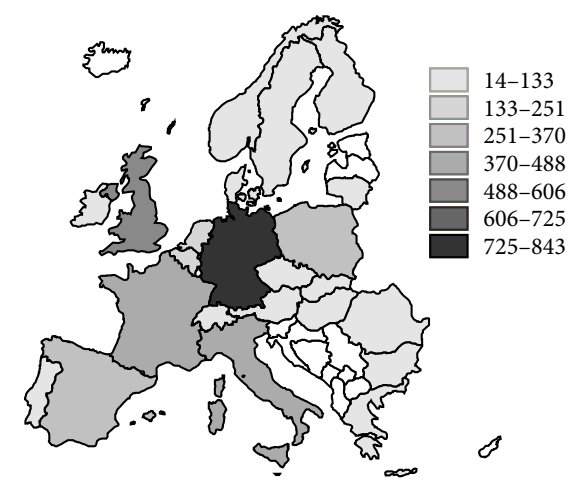

$\mathrm{CO}_{2}$

Fig. 9. $\mathrm{PEC}$ in million tonnes of oil equivalent and $\mathrm{CO}_{2}$ in million tonnes

Table 1. Descriptive statistics of research sample

\begin{tabular}{lccccc}
\hline \multicolumn{1}{c}{ Variable } & Unit & Mean & Max & Min & Std. err. \\
\hline Labour force (LF) & Thousand & 15962.83 & 53937.50 & 1983.6 & 16462.71 \\
\hline Primary energy consumption (PEC) & $\begin{array}{c}\text { Million tonnes } \\
\text { oil equivalent }\end{array}$ & 76.68 & 325.02 & 5.67 & 81.33 \\
\hline Gross domestic product (GDP) & Million euro & 598847.4 & 2737600.0 & 34631.2 & 712136.9 \\
\hline $\mathrm{CO}_{2}$ emissions $\left(\mathrm{CO}_{2}\right)$ & $\begin{array}{l}\text { Million tonnes } \\
\text { carbon dioxide }\end{array}$ & 176.86 & 842.82 & 14.81 & 198.29 \\
\hline
\end{tabular}

European countries generally can be divided into two groups in terms of the selected characteristics (LF, GDP, PEC, $\mathrm{CO}_{2}$ ). This confirms the k-means analysis performed with the use of the Statistica application. The first group consists of countries with the highest value of GDP, $\mathrm{CO}_{2}$ and PEC: Germany, France, United Kingdom and Italy. The others form the second group. The average values in the two groups are shown in Table 2. Later, the compliance of the groups obtained by k-means with the ones on the basis of DEA will be discussed.

Moreover, as can be seen, the high value of LF is connected to the high value of PEC and generates not only high GDP but also $\mathrm{CO}_{2}$. The linear relationships between these variables, measured by correlation coefficients, are shown in Table 3 .

Table 2. Average values in the groups

\begin{tabular}{ccc}
\hline Variable & Group 1 & Group 2 \\
\hline LF & 43485 & 10458 \\
\hline GDP & 2064144 & 305788 \\
\hline PEC & 233 & 45 \\
\hline $\mathrm{CO}_{2}$ & 531 & 106 \\
\hline
\end{tabular}

Table 3. Correlation coefficients

\begin{tabular}{llll}
\hline & GDP & PEC & CO2 \\
\hline LF & 0.847 & 0.908 & 0.914 \\
\hline GDP & & 0.974 & 0.921 \\
\hline PEC & & & 0.962 \\
\hline
\end{tabular}


There are high correlation coefficients between all variables. There is no possibility to have high GDP without consuming energy and without $\mathrm{CO}_{2}$ emission. Thus, the assumptions on null-joint and weakly disposable outputs are met.

\section{Research results}

Scores in expressed in percents for 24 European countries, estimated with the use of the environmental DEA methodology, are presented in Table 4. The environmental DEA method was compared with the classical DEA model, taking 3 inputs: LF, PEC, $\mathrm{CO}_{2}$. The DEA with 3 inputs considers $\mathrm{CO}_{2}$ emission as a necessary input to obtain GDP and an assumption of strong disposability of it.

When comparing the environmental DEA scores with the results of the basic DEA model, taking $\mathrm{CO}_{2}$ as the third input, a strong relationship was noted. The Pearson correlation coefficient between the rankings is 0.909 . However, environmental DEA evaluates countries more severely in terms of $\mathrm{CO}_{2}$ emissions.

Table 4. Productivity of European countries estimated by DEA

\begin{tabular}{lcccc}
\hline \multicolumn{1}{c}{ Unit } & The 2-letter codes & Environmental DEA & $\lambda_{\text {Switzerland }}$ & DEA with 3 inputs \\
\hline Austria & AT & $40.2 \%$ & 0.639 & $60.20 \%$ \\
\hline Belgium & BE & $24.3 \%$ & 0.782 & $52.90 \%$ \\
\hline Bulgaria & BG & $8.7 \%$ & 0.082 & $14.40 \%$ \\
\hline Czech Republic & CZ & $12.4 \%$ & 0.305 & $22.90 \%$ \\
\hline Denmark & DK & $50.6 \%$ & 0.508 & $84.90 \%$ \\
\hline Finland & F & $36.6 \%$ & 0.395 & $57.50 \%$ \\
\hline France & FR & $48.4 \%$ & 4.207 & $56.00 \%$ \\
\hline Germany & DE & $29.4 \%$ & 5.591 & $55.30 \%$ \\
\hline Greece & GR & $20.9 \%$ & 0.372 & $41.20 \%$ \\
\hline Hungary & HU & $18.9 \%$ & 0.200 & $29.50 \%$ \\
\hline Ireland & IE & $42.0 \%$ & 0.335 & $75.70 \%$ \\
\hline Italy & IT & $36.9 \%$ & 3.186 & $60.50 \%$ \\
\hline Lithuania & LT & $21.2 \%$ & 0.071 & $37.60 \%$ \\
\hline Netherlands & NL & $22.9 \%$ & 1.231 & $56.00 \%$ \\
\hline Norway & NO & $100.0 \%$ & 0.000 & $100.00 \%$ \\
\hline Poland & PL & $10.7 \%$ & 0.796 & $24.00 \%$ \\
\hline Portugal & PT & $28.7 \%$ & 0.338 & $42.90 \%$ \\
\hline Romania & RO & $16.9 \%$ & 0.290 & $26.50 \%$ \\
\hline Slovakia & SK & $18.8 \%$ & 0.147 & $26.80 \%$ \\
\hline Spain & ES & $32.6 \%$ & 2.089 & $47.10 \%$ \\
\hline Sweden & SE & $72.1 \%$ & 0.859 & $74.20 \%$ \\
\hline Switzerland & CH & $100.0 \%$ & 1.000 & $100.00 \%$ \\
\hline Turkey & TR & $17.0 \%$ & 1.262 & $31.00 \%$ \\
\hline United & GB & $33.5 \%$ & 3.878 & $58.50 \%$ \\
\hline Kingdom & & & \\
\hline
\end{tabular}


Analyzing the relationship between the productivity and the variables, it can be noticed that it is not strongly correlated with any variable. However, there is a linear relationship between the calculated productivity and the GDP per $\mathrm{CO}_{2}$, LF, and PEC. The correlation coefficients between productivity and selected variables are shown in Table 5.

Table 5. Correlation Coefficient

\begin{tabular}{cc}
\hline LF & -0.169 \\
\hline GDP & 0.100 \\
\hline PEC & -0.027 \\
\hline CO2 & -0.157 \\
\hline GDP/LF & 0.906 \\
\hline GDP/PEC & 0.738 \\
\hline GDP/CO2 & 0.987 \\
\hline
\end{tabular}

Through the DEA, the potential improvements of inefficient units can be identified. Defining technology as a vector of inputs and outputs, the target technology that guarantees $100 \%$ efficiency can be determined by the peer object (Guzik 2009):

where:

$$
T_{O}^{\star}=\sum_{i=1}^{I} \lambda_{i} T_{i},
$$

$\lambda_{i}$ - non-negative optimal weight for $i=1, . ., I$ object;

$T_{i}-i$-th object technology.

Optimal, benchmark technology of each analyzed country (except fully efficient Norway) is consistent only with the values for Switzerland. Adequate $\lambda\left(\lambda_{\text {Switzerland }}\right)$ are presented in Table 4.

Switzerland appears in optimal technology for each country as an outlier, which is a rather peerless benchmark for other states (Fig. 10). In this case, applying the benchmarking graph to determine the object of the model for not fully efficient units in order to make them perform according to their optimal technology, as shown e.g. in (Nazarko, Šaparauskas 2014), has a limited use.

However, the benchmark approach for the DEA method allows to identify the technological competitors both for the inefficient objects, as well as for the efficient objects. However, it should be emphasized that the interpretation of the concept of a technological competitor in the DEA is different from the classic definition of a market participant who competes with other players trying to achieve its goals. It cannot be regarded as a competition for resources, but rather as a place in the ranking. Technological competition in the DEA is rather a competitive position among the analyzed units. The competitors can be determined through the use of the Super Efficiency (SE) DEA model solutions, formulated with exclusion of fully efficient objects. The technological competitors of inefficient object are other inefficient objects that create optimal technology for the object (Guzik 2009). In the article, the SE DEA model proposed by P. Anderson and N.C. Petersen (1993) was used. It involves the exclusion of the analyzed object technology in the optimization. The 
consequence is no limit efficiency equal to 1 . The model was altered for the needs of the case of the existence of desirable and undesirable results:

$$
\begin{gathered}
\min \theta ; \\
\sum_{i=1 \neq O}^{I} \lambda_{i} x_{i m} \leq x_{O m}, m=1, \ldots, M ; \\
\sum_{i=1 \neq O}^{I} \lambda_{i} y_{i n} \geq y_{O n}, n=1, \ldots, N ; \\
\sum_{i=1 \neq O}^{I} \lambda_{i} q_{i j} \leq \theta q_{O j}, j=1, \ldots, J ; \\
\lambda_{i} \geq 0, i=1, \ldots, I,
\end{gathered}
$$

where: symbols as in equation 2 .

The technological competitors for European countries have been identified, using the optimal $\lambda$ values, illustrated in Figure 11. The visualization shows 10 groups of competitors. Switzerland and Norway are fully efficient. It is evident, that each of the groups includes competitors with increasingly lower values of the efficiency ratio. The arrows show the direction of desire imitation, and indicate which objects should serve as model objects.

Searching for the causes, explaining the differences in environmental performance scores, the hypothesis was tested that the countries which dedicated a higher value of Gross Domestic expenditure to R\&D in \% are characterized by higher environmental performance.

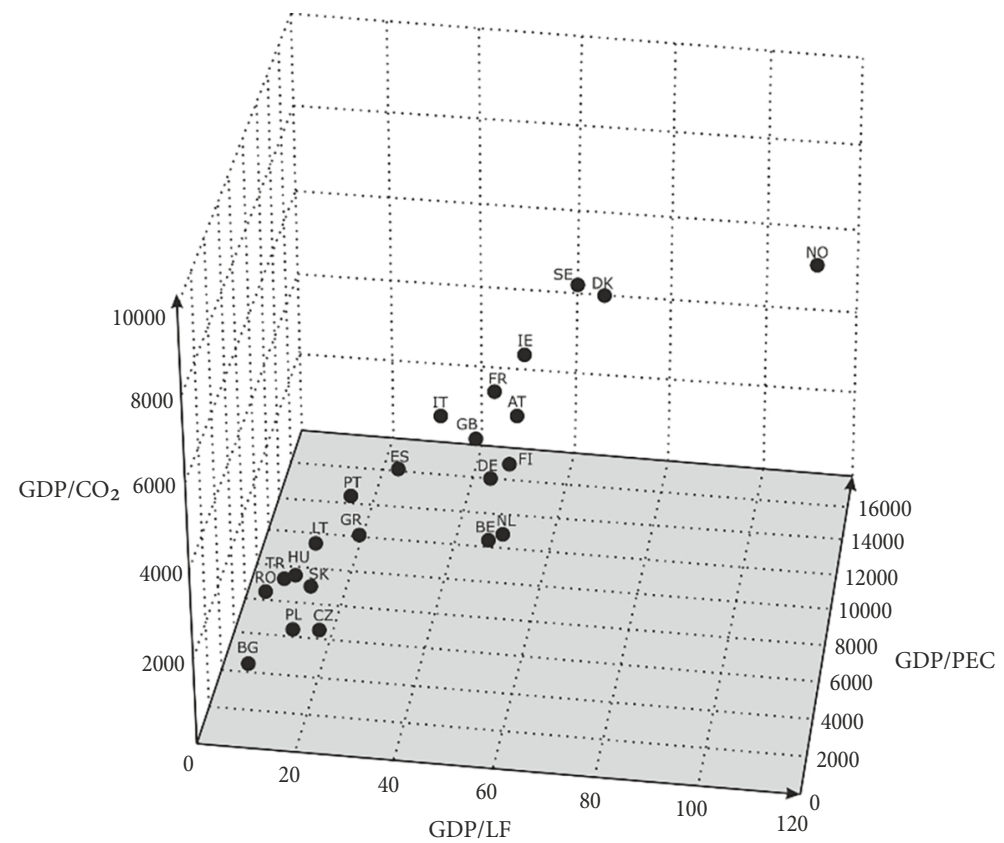

Fig. 10. PEC in million tonnes oil equivalent and $\mathrm{CO}_{2}$ in million tonnes 


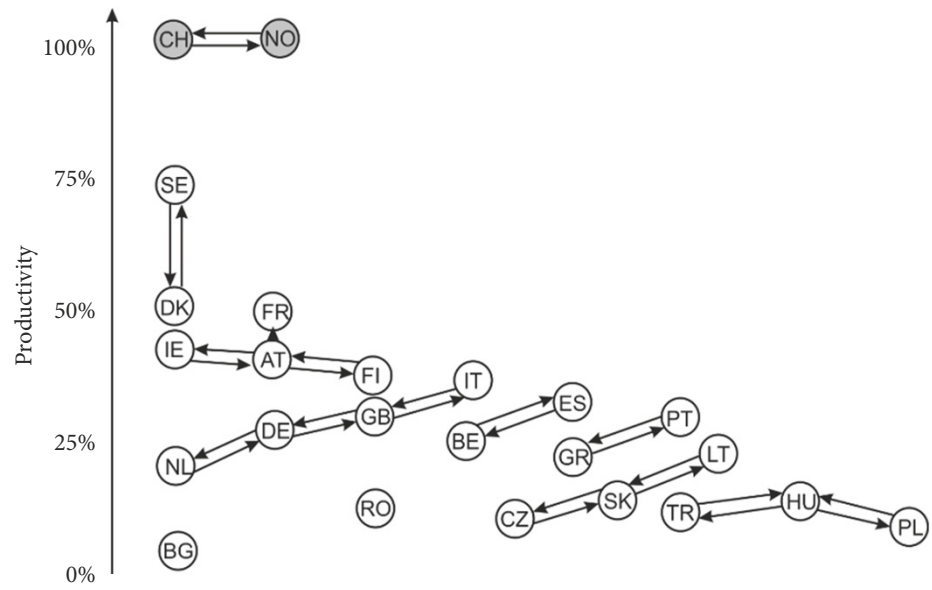

Fig. 11. Groups of technological competitors

In this work, the standard Tobit model (4) was applied, with a dependent variable on the left limited at 0 , and transformed data. Logarithmic transformation and linear combination with the coefficient -1 of the dependent variable $Y$ created a new variable $Z=-\ln (Y)$ that has value in range of $[0, \infty)$. The statistics of Tobit model were obtained using the EasyReg (by H. J. Bierens 2015) and are presented in Table 6.

Table 6. Tobit regression statistics

\begin{tabular}{lccc}
\hline & Estimated & t-value & p-value \\
\hline Intercept & 2.0551988 & 6.3028 & 0.00000 \\
\hline \% GDP expenditure on R\&D & -46.491214 & -3.8492 & 0.00012 \\
\hline Pseudo R ${ }^{2}$ & 0.38925 & & \\
\hline Log likehood & 19.797520 & & \\
\hline Standard error of e & 0.5515574 & 6.3028 & 0.00000 \\
\hline
\end{tabular}

Because of the transformation, a negative coefficient of an explanatory variable implies a positive effect on the original dependent variable - efficiency score. Pseudo $\mathrm{R}^{2}$ is small but the $t$-statistic large enough with the associated p-value near to 0 allow to assume that the percentage of GDP expenditure on R\&D can influence the efficiency score. Being conscious of small degrees of freedom in the Tobit model, it can be said that the higher percent of GDP expenditure on $R \& D$, the higher the efficiency score.

\section{Conclusions}

The awareness of the impact of people's activities on the environment is the cause of the increasing understanding of the need for sustainable development, and hence the popularity of the use of the benchmarking methods in the assessment of the productivity of economic growth, taking into account the aspect of the simultaneous negative impact on 
the environment. In recent years, among the wide range of existing approaches toward environmental performance indicators, environmental DEA technology has gained high popularity. Not only, DEA has being used to assess the status of sustainable development but also to identify technologies with the greatest potential for development with respect to environment (Halicka 2016).

In the article, the DEA methodology was systematized, described, and presented with the use of original three-dimensional charts - which is an additional, advantage of this work.

In the study, the REI model was implemented for the assessment of the environmental performance of European countries. High compatibility of REI indicators with the results of the standard model of the DEA shows that sometimes it is possible to start with the standard model of the DEA and in many cases it may be sufficient. The performed evaluation in terms of GDP compared to the costs was positive in the case of only 2 countries. According to the obtained results, European countries are highly diversified with regard to the efficiency of environmental performance. The average efficiency is low and amounts only to 0.3515 (median 0.2906 ). This leads to the conclusion that the increase in efficiency is possible. Most countries require changes in the existing model of development in order to reduce emissions and become more environmentally friendly. However, according to the benchmarks, the two best, fully efficient countries are located outside the European Union and because of the difference in the score, are rather out of reach.

Therefore, the authors proposed the formulation of groups on the basis of the concept of technological competition according to the SE DEA model. By grouping the countries as regards the optimal technology, the nearest peer can be indicated, and thereby, possible improvements may be determined. The environmental DEA model integrated with a relatively unpopular method of determining the competitor's technology, is an approach which the authors have not encountered so far in the literature.

The DEA rating is definitely different from the one obtained by k-means. The ones ranking high with respect to absolute GDP, $\mathrm{PEC}$ and $\mathrm{CO}_{2}$ are not high in the ranking of environmental performance, but they are rather mediocre: France occupies the $5^{\text {th }}$ place, Italy $8^{\text {th }}$, UK $10^{\text {th }}$, and Germany 12 th. In other words, the stereotyped country rating on the basis of the only $\mathrm{CO}_{2}$ or GDP may be unfair in many cases.

The conducted study utilizing the environmental DEA took into account the indicators most frequently used to assess sustainability: GDP, $\mathrm{CO}_{2}$, LG, PEC. An innovative approach is an attempt to determine the relationship between the final result and expenditure and the R\&D. The choice of this variable was made in the context of compliance with the repeatedly indicated priority areas of action in the directives of the European Commission. The choice was also motivated by frequent discussions concerning the need to invest in innovation in order to increase the competitiveness of economies and a threat to the entire European manufacturing and service sector in the event of abandonment of research and development support.

There is no strong relationship between $\mathrm{R} \& \mathrm{D}$ expenditure and the level of environmental performance but the Tobit model indicates the existence of such link. However, one should be aware that far-reaching conclusions are limited by small degrees of freedom in the estimated Tobit regression model. 
To sum up, environmental performance measurements may provide quantitative information for environmental policy analysis and decision making. It is also worth to analyze other factors that affect environmental performance of economies. A valuable approach would be to precede the quantitative analysis with scenario method (Nazarko, Kononiuk 2013). In principle, only an interdisciplinary combinations of different research methods, provide necessary conditions for a proper assessment of the development with respect to environmental and social needs (Ejdys et al. 2015).

\section{References}

Andersen, P.; Petersen, N. C. 1993. A procedure for ranking efficient units in data envelopment analysis, Management Science 39(10): 1261-1264. https://doi.org/10.1287/mnsc.39.10.1261

Baležentis, T.; Li, T.; Štreimikiene, D.; Baležentis, A. 2016. Is the Lithuanian economy approaching the goals of sustainable energy and climate change mitigation? Evidence from DEA-based environmental performance index, Journal of Cleaner Production 116: 23-31.

https://doi.org/10.1016/j.jclepro.2015.12.088

Bierens, H. J. 2015. Free Econometrics Software [online], [cited 8 November 2016]. Available from Internet: http://personal.psu.edu/hxb11/EASYREG.HTM

BP Statistical Review of World Energy. 2014. [online], [cited 18 September 2014]. Available from Internet: http://www.bp.com/en/global/corporate/about-bp/energy-economics/statistical-review-ofworld-energy/statistical-review-downloads.html

Callens, I.; Tyteca, D. 1999. Towards indicators of sustainable development for firms. A productive efficiency perspective, Ecological Economics 28(1): 41-53.

https://doi.org/10.1016/s0921-8009(98)00035-4

Charnes, A.; Cooper, W. W.; Rhodes, E. 1978. Measuring the efficiency of decision making units, European Journal of Operational Research 2(6): 429-444. https://doi.org/10.1016/0377-2217(78)90138-8

Cooper, W. W.; Seiford, L. M.; Tone, K. 2007. Data envelopment analysis. A comprehensive text with models, applications, references and DEA-solver software. 2nd ed. Springer.

Ejdys, J.; Ustinovicius, L.; Stankevičienè, J. 2015. Innovative application of contemporary management methods in a knowledge-based economy - interdisciplinarity in science, Journal of Business Economics and Management 16(1): 261-274. https://doi.org/10.3846/16111699.2014.986192

Eurostat. 2014. [online], [cited 18 September 2014]. Available from Internet: http://epp.eurostat. ec.europa.eu/portal/page/portal/statistics/search_database.

EPA, United States Environmental Protection Agency. 2014. [online], [cited 18 September 2014]. Available from Internet: http://www.epa.gov/climatechange/ghgemissions/global.html.

Färe, R.; Grosskopf, S.; Hernandez-Sancho, F. 2004. Environmental performance: an index number approach, Resource and Energy Economics 26(4): 343-352.

https://doi.org/10.1016/j.reseneeco.2003.10.003

Färe, R.; Grosskopf, S.; Tyteca, D. 1996. An activity analysis model of the environmental performance of firms application to fossil-fuel-fired electric utilities, Ecological Economics 18(2): 161-175. https://doi.org/10.1016/0921-8009(96)00019-5

Färe, R.; Grosskopf, S.; Lovell, C. A. K.; Pasurka, C. 1989. Multilateral productivity comparisons when some outputs are undesirable: a nonparametric approach, Review of Economics and Statistics 71: 90-98. https://doi.org/10.2307/1928055

Guo D.; Wu J. 2013. A complete ranking of DMUs with undesirable outputs using restrictions in DEA models, Mathematical and Computer Modelling 58(5-6): 1102-1109.

https://doi.org/10.1016/j.mcm.2011.12.044 
Guzik, B. 2009. Podstawowe modele DEA w badaniu efektywności gospodarczej i społecznej. Wydawnictwo Uniwersytetu Ekonomicznego w Poznaniu, Poznań (in Polish)

Halicka, K. 2016. Innovative classification of methods of the future-oriented technology analysis, Technological and Economic Development of Economy 22(4): 574-597.

Li, M.; Wang, Q. 2014. International environmental efficiency differences and their determinants, Energy 78: 411-420. https://doi.org/10.1016/j.energy.2014.10.026

Li, H.; Shi, J. 2014. Energy efficiency analysis on Chinese industrial sectors: an improved Super-SBM model with undesirable outputs, Journal of Cleaner Production 65: 97-107. https://doi.org/10.1016/j.jclepro.2013.09.035

Lin, B.; Fei, R. 2015. Regional differences of CO2 emissions performance in China's agricultural sector: a Malmquist index approach, European Journal of Agronomy 70: 33-40. https://doi.org/10.1016/j.eja.2015.06.009

Lozano, S.; Gutiérrez, E. 2008. Non-parametric frontier approach to modelling the relationships among population, GDP, energy consumption and CO2 emissions, Ecological Economics 66(4): 687-699. https://doi.org/10.1016/j.ecolecon.2007.11.003

Makridou, G.; Andriosopoulos, K.; Doumpos, M.; Zopounidis, C. 2016. Measuring the efficiency of energy-intensive industries across European countries, Energy Policy 88: 573-583.

https://doi.org/10.1016/j.enpol.2015.06.042

Meng, F. Y.; Fan, L. W.; Zhou P.; Zhou D. Q. 2013. Measuring environmental performance in China's industrial sectors with non-radial DEA, Mathematical and Computer Modelling 58(5-6): 1047-1056. https://doi.org/10.1016/j.mcm.2012.08.009

Nazarko, J.; Kononiuk, A. 2013. The critical analysis of scenario construction in the Polish foresight initiatives, Technological and Economic Development of Economy 19(3): 510-532. https://doi.org/10.3846/20294913.2013.809030

Nazarko, J.; Šaparauskas, J. 2014. Application of DEA method in efficiency evaluation of public higher education institutions, Technological and Economic Development of Economy 20(1): 25-44. https://doi.org/10.3846/20294913.2014.837116

Sueyoshi, T.; Goto, M.; Ueno, T. 2010. Performance analysis of US coal-fired power plants by measuring three DEA efficiencies, Energy Policy 38(4): 1675-1688. https://doi.org/10.1016/j.enpol.2009.11.017

Sueyoshi, T.; Yuan, Y. 2015. Comparison among U.S. industrial sectors by DEA environmental assessment: Equipped with analytical capability to handle zero or negative in production factors, Energy Economics 52(Part A): 69-86. https://doi.org/10.1016/j.eneco.2015.09.006

Tobin, J. 1958. Estimation of relationships for limited dependent variables, Econometrica 26(1): 24-36. https://doi.org/10.2307/1907382

Tyteca, D. 1996. On the measurement of the environmental performance of firms - a literature review and a productive efficiency perspective, Journal of Environmental Management 46(3): 281-308. https://doi.org/10.1006/jema.1996.0022

Wang, Q.; Zhao, Z.; Shen, N.; Liu, T. 2015. Have Chinese cities achieved the win-win between environmental protection and economic development? From the perspective of environmental efficiency, Ecological Indicators 51: 151-158. https://doi.org/10.1016/j.ecolind.2014.07.022

Wang, K.; Yu, S.; Zhang, W. 2013. China’s regional energy and environmental efficiency: a DEA window analysis based dynamic evaluation, Mathematical and Computer Modelling 58(5-6): 1117-1127. https://doi.org/10.1016/j.mcm.2011.11.067

Wu, F.; Fan, L. W.; Zhou, P.; Zhou, D. Q. 2012. Industrial energy efficiency with CO2 emissions in China: a nonparametric analysis, Energy Policy 49: 164-172. https://doi.org/10.1016/j.enpol.2012.05.035

Yang, H.; Pollitt, M. 2010, The necessity of distinguishing weak and strong disposability among undesirable outputs in DEA underline inter alia environmental performance of Chinese coal-fired power plants, Energy Policy 38(8): 4440-4444. https://doi.org/10.1016/j.enpol.2010.03.075 
Yang, L.; Ouyangb, H.; Fang, K.; Ye, L.; Zhang, J. 2015. Evaluation of regional environmental efficiencies in China based on super-efficiency-DEA, Ecological Indicators 51: 13-19.

https://doi.org/10.1016/j.ecolind.2014.08.040

Zaim, O.; Taskin, F. 2000. Environmental efficiency in carbon dioxide emissions in the OECD: a nonparametric approach, Journal of Environmental Management 58(2): 95-107. https://doi.org/10.1006/jema.1999.0312

Zhou, P.; Ang, B. W.; Poh, K. L. 2008a. Measuring environmental performance under different environmental DEA technologies, Energy Economics 30(1): 1-14. https://doi.org/10.1016/j.eneco.2006.05.001

Zhou, P.; Ang, B. W.; Poh, K. L. 2008b. A survey of data envelopment analysis in energy and environmental studies, European Journal of Operational Research 189(1): 1-18. https://doi.org/10.1016/j.ejor.2007.04.042

Zhou, P.; Ang, B. W.; Wang, H. 2012. Energy and CO2 emission performance in electricity generation: a non-radial directional distance function approach, European Journal of Operational Research 221(3): 625-635. https://doi.org/10.1016/j.ejor.2012.04.022

Zhou, P.; Poh, K. L.; Ang, B. W. 2007. A non-radial DEA approach to measuring environmental performance, European Journal of Operational Research 178(1): 1-9. https://doi.org/10.1016/j.ejor.2006.04.038

Ewa CHODAKOWSKA. Received her PhD degree in management sciences from the Faculty of Management at the Warsaw University. Member of the IEEE Systems, Man, and Cybernetics Society, Section of Classification and Data Analysis of the Polish Statistical Association and the Polish Society of Production Management. Area of research interests: productivity, data analysis, forecasting and data science.

Joanicjusz NAZARKO is a Professor of both technical and economic sciences, ordinary member of the Polish Academy of Engineering and a Presidium member of the Production Engineering Committee of the Polish Academy of Sciences. He is currently serving as the Director of International China and Central-Eastern Europe Institute of Logistics and Service Science. He also holds the posts of an Professeur Associé at the Université du Québec à Trois-Rivières (Canada) and an Honorary Professor of Zhejiang University Ningbo Institute of Technology (China). He was a Rector of Bialystok University of Technology in the years 2005-2008. His academic interests include technology foresight, forecasting, modelling and simulation in technical and economic systems, logistic systems as well productivity analysis and benchmarking. He is the author or co-author of more than 200 technical and scholarly works published in reputable journals. He regularly speaks and presents his work at numerous Polish and international conferences. He has been a visiting professor at universities in China, Finland, Great Britain, Canada, Germany, Lithuania and USA. 